\title{
COMPARISION OF ANTIOXIDANT ACTIVITY OF ACTINIDIA DELICIOSA AND PSIDIUM GUAJAVA USING FERRIC REDUCING ANTIOXIDANT POWER ASSAY METHOD
}

\author{
CAROLINE JEBA R*, INDHUJA D
}

Department of Biotechnology, Dr. M.G.R. Educational and Research Institute, Chennai, Tamil Nadu, India. Email: janeshjeba@gmail.com

Received: 30 January 2020, Revised and Accepted: 01 April 2020

ABSTRACT

Objectives: Antioxidant activity was studied in naturally dried seed extract and hot air oven dried extract of Actinidia deliciosa and Psidium guajava using ferric reducing antioxidant power (FRAP) assay method.

\begin{abstract}
Methods: The dried powdered seed of $A$. deliciosa and $P$. guajava $10 \mathrm{~g}$ was dissolved in $100 \mathrm{ml}$ of ethanol in four different conical flasks $\mathrm{S} 1$ (for naturaly dried seeds of $A$. deliciosa), S2 (for hot air oven-dried seeds of A. deliciosa), S3 (for naturally dried seeds of $P$. guajava), and S4 (for hot air oven-dried seeds of $P$. guajava). The extract was carried out in shaker at $120 \mathrm{rpm}$ for $72 \mathrm{~h}$ at room temperature by mild shaking. The extract was taken out and centrifuged at $4000 \mathrm{rpm}$ for $10 \mathrm{~min}$, the supernatant was taken out. The supernatant was placed in a water bath at $95^{\circ} \mathrm{C}$ for the solvent to evaporate and stored at room temperature.
\end{abstract}

Results: According to the FRAP results, P. guajava which was naturally dried and extracted has shown the highest antioxidant activity (sample 3) then followed by the samples S4, S1, and S2. The least activity is observed in the sample (S2).

Conclusion: By comparing the antioxidant activity between the A. deliciosa and P. guajava with the help of FRAP assay results, $P$. guajava has the highest amount of vitamin C (responsible for antioxidant activity) when compared to that of the A. deliciosa.

Keywords: Actinidia deliciosa, Psidium guajava, Ferric reducing antioxidant power, Antioxidant assay.

(C) 2020 The Authors. Published by Innovare Academic Sciences Pvt Ltd. This is an open access article under the CC BY license (http://creativecommons. org/licenses/by/4. 0/) DOI: http://dx.doi.org/10.22159/ajpcr.2020.v13i5.36981

\section{INTRODUCTION}

Actinidia deliciosa (Kiwi fruit) is said to be a dietary powerhouse because of the presence of proteins, fats, carbohydrates, minerals, vitamins, and natural fiber [1]. Kiwi is also rich in Vitamin C which is responsible for its antioxidant activity. Due to the excellent folate content, it is beneficial for pregnant women. A. deliciosa also loaded with minerals consisting of potassium which assists to maintain blood stress and increase strength. In addition, kiwifruit includes a soluble enzyme known as Actinidia which facilitates inside the digestion of proteins and relieves the bloated feeling. Kiwifruits are the simplest fruit containing the actinidin enzyme, making them particular and an absolute have to have for your daily fruit basket [2]. These fruits are responsible for controlling blood sugar because it is characterized by a low glycemic index. Kiwifruit may support immune function and reduce the incidence and severity of cold- or flu-like illness in atrisk groups such as older adults and children. However, kiwifruit is allergenic, and although symptoms in most susceptible individuals are mild, severe reactions have been reported. While many research gaps remain, kiwifruit with their multiple health benefits has the potential to become part of our daily prescription for health [3]. Antioxidant activity study provides original data on the compositional profile and antioxidant capacity of kiwifruit grown in five orchards of the largest Italian production area (Lazio region). Data on macronutrients (moisture, protein, lipid, and carbohydrate), starch, total dietary fiber, oxalic acid, organic acids, minerals, trace elements, and bioactive molecules, including ascorbic acid, total polyphenols, carotenoids (lutein and $\beta$-carotene), and tocols ( $\alpha$-tocopherol, $\gamma$-tocopherol, and $\gamma$-tocotrienol) content are reported. Kiwifruit was rich in ascorbic acid (mean value $60 \mathrm{mg} / 100 \mathrm{~g}$ ). Lutein was the most abundant carotenoid (mean value $0.2 \mathrm{mg} / 100 \mathrm{~g}$ ) followed by b-carotene. Among tocols, a-tocopherol was the most abundant (mean value $0.9 \mathrm{mg} / 100 \mathrm{~g}$ ) followed by $\gamma$-tocotrienol (mean value $0.12 \mathrm{mg} / 100 \mathrm{~g}$ ). The antioxidant activity (evaluated by means of ferric reducing antioxidant power [FRAP], ABTS, oxygen radical absorbance capacity assays) was significantly higher $(P<0.05)$ in Borgo Podgora orchard than in any other one, the fruit of this orchard showed also the highest bioactive molecules content. Antioxidant activity positively correlated with hydrophilic molecules content mostly with ascorbic acid $(r=0.97)$, suggesting Vitamin $C$ as the major contributor to the total antioxidant activity in kiwifruit [4].

Psidium guajava (guava) is called as super fruits because of the presence of folic acid, flavonoids, manganese, copper, Vitamin A, Vitamin C, and potassium. Lycopene is present in guava fruit which fights against free radical and stops the dangers of heart disease and several types of cancer. P. guajava is recognized to combat off lung and oral cancers too [5]. Consuming guava helps in tightening of pores in the skin and also helps to remove wrinkles. The fruit also consists of natural fiber which removes constipation and hemorrhoids. All parts of the plant have been used for different purposes: Hepatoprotection, antioxidant, anti-inflammatory, antispasmodic, anti-cancer, antimicrobial, anti-hyperglycemic, analgesic, endothelial progenitor cells, anti-stomach-ache, and anti-diarrhea. P. guajava has many effects on health and that it should be researched more extensively in clinical trials. Furthermore, leaves, seeds, and peel are treated as wastes by the food processing industry and are discarded, so their use may reduce the disposal of these parts of $P$. guajava as pollutants [6]. Many pharmacological studies have demonstrated the ability of this plant to exhibit antioxidant, hepatoprotection, anti-allergy, antimicrobial, antigenotoxic, antiplasmodial, cytotoxic, antispasmodic, cardioactive, anticough, antidiabetic, anti-inflammatory, and antinociceptive activities, supporting its traditional uses and wide range of clinical applications for the treatment of infantile rotaviral enteritis, diarrhea, and diabetes [7]. Pedilanthus tithymaloides showed significant free radical scavenging activity using FRAP assay [8]. 


\section{MATERIALS AND METHODS}

A. deliciosa and P. guajava were collected from the Koyambedu market. The plant was authenticated by Prof. P. Jayaraman, Director, Institue of Herbal botany, Plant Anatomy and Research Centre, Chennai-45.

\section{Fruit extract preparation}

Extraction is a process used for separating bioactive constituents from solutions using specific solvents by adopting standard procedures [9].

Fruits were rinsed with distilled water and extracted the seeds manually with the help of a spatula. The flesh around the seeds was removed with the help of muslin cloth. Both the fruits were dried naturally and by hot air oven. Ground the seeds into a fine powder. Ten gram of seed powder was mixed with $100 \mathrm{ml}$ of ethanol and it was placed in the shaker for $72 \mathrm{~h}$ in $120 \mathrm{rpm}$ after taking the solvent out centrifuge in $4000 \mathrm{rpm}$ for $10 \mathrm{~min}$.

\section{Antioxidant assay}

FRAP assay

The FRAP assay measures the antioxidant potential in samples through the reduction of ferric iron $\left(\mathrm{Fe}^{3+}\right)$ to ferrous iron $\left(\mathrm{Fe}^{2+}\right)$ by antioxidants present in the samples. Following the reduction of the ferric iron, a blue color develops that is read calorimetrically at $594 \mathrm{~nm}$.

Table 1: Ferric reducing antioxidant power assay of naturally dried guava extract

\begin{tabular}{lll}
\hline Concentration $(\boldsymbol{\mu g} / \mathbf{m l})$ & OD\% & Sample OD \\
\hline 20 & 71.16 & 0.482 \\
40 & 72.03 & 0.497 \\
60 & 73.67 & 0.528 \\
80 & 75.65 & 0.571 \\
100 & 77.25 & 0.611 \\
120 & 78.21 & 0.638 \\
\hline
\end{tabular}

Table 2: Ferric reducing antioxidant power assay of naturally dried kiwi extract

\begin{tabular}{lll}
\hline Concentration $(\boldsymbol{\mu g} / \mathbf{m L})$ & OD\% & Sample OD \\
\hline 20 & 66.35 & 0.434 \\
40 & 81.77 & 0.801 \\
60 & 82.92 & 0.855 \\
80 & 83.72 & 0.897 \\
100 & 84.36 & 0.934 \\
120 & 85.65 & 1.018 \\
\hline
\end{tabular}

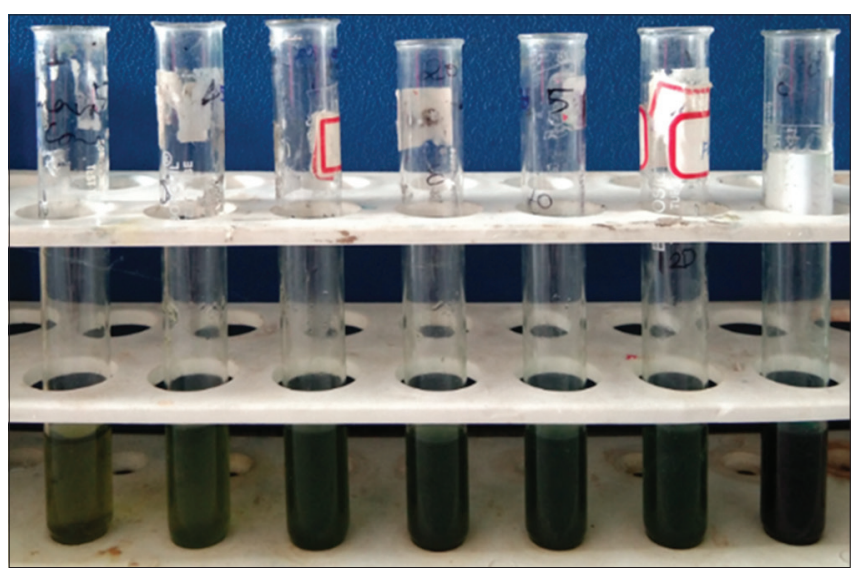

Fig. 1: Ferric reducing antioxidant power assay of naturally dried guava extract

\section{FRAP assay}

The reducing power of the test sample was determined by $\mathrm{Fe}^{3+}$ reduction method with slight modification. One milliliter of three test samples of different concentrations $(20-120 \mu \mathrm{g} / \mathrm{ml})$ was mixed with $1 \mathrm{ml}$ of phosphate buffer $(0.2 \mathrm{M}, \mathrm{pH} 6.6)$ and $1 \mathrm{ml}$ of potassium ferricyanide [K3Fe $(\mathrm{CN}) 6](1 \% \mathrm{w} / \mathrm{v})$. The mixtures were then incubated at $50^{\circ} \mathrm{C}$ in a water bath for $30 \mathrm{~min} .0 .5 \mathrm{~mL}$ of trichloroacetic acid $(10 \% \mathrm{w} / \mathrm{v})$ was added to each mixture. Then, $0.1 \mathrm{ml}$ of freshly prepared $\mathrm{FeCl}_{3}$ $(0.1 \% \mathrm{w} / \mathrm{v})$ solution was added and the absorbance was measured at $700 \mathrm{~nm}$ in UV-Vis spectrophotometer (Oyaizu, M. 1986) [10]. The percentage of reduction was calculated as:

\section{(Sample OD - Control OD)/Sample OD×100.}

Antioxidant activity is found to be linearly proportional with phenolic contents [11].

\section{Sample preparation}

The dried powdered seed of $A$. deliciosa and P. guajava $10 \mathrm{~g}$ was dissolved in $100 \mathrm{ml}$ of ethanol in four different conical flasks S1 (for naturally dried seeds of $A$. deliciosa), S2 (for hot air oven-dried seeds of A. deliciosa), S3 (for naturally dried seeds of P. guajava), and S4 (for hot air oven-dried seeds of $P$. guajava). The extract was carried out in shaker at $120 \mathrm{rpm}$ for $72 \mathrm{~h}$ at room temperature by mild shaking. The extract

Table 3: Ferric reducing antioxidant power assay of hot air oven-dried guava extract

\begin{tabular}{lll}
\hline Concentration $(\boldsymbol{\mu g} / \mathbf{m l})$ & OD\% & Sample OD \\
\hline 20 & 69.38 & 0.454 \\
40 & 71.22 & 0.483 \\
60 & 72.69 & 0.509 \\
80 & 74.4 & 0.543 \\
100 & 76.91 & 0.602 \\
120 & 77.9 & 0.6229 \\
\hline
\end{tabular}

Table: 4 Ferric reducing antioxidant power assay of hot air oven-dried kiwi extract

\begin{tabular}{lll}
\hline Concentration $(\boldsymbol{\mu g} / \mathrm{ml})$ & OD\% & Sample OD \\
\hline 20 & 62.5 & 0.389 \\
40 & 81.61 & 0.794 \\
60 & 82.26 & 0.823 \\
80 & 83.31 & 0.875 \\
100 & 84.11 & 0.919 \\
120 & 85.2 & 0.987 \\
\hline
\end{tabular}

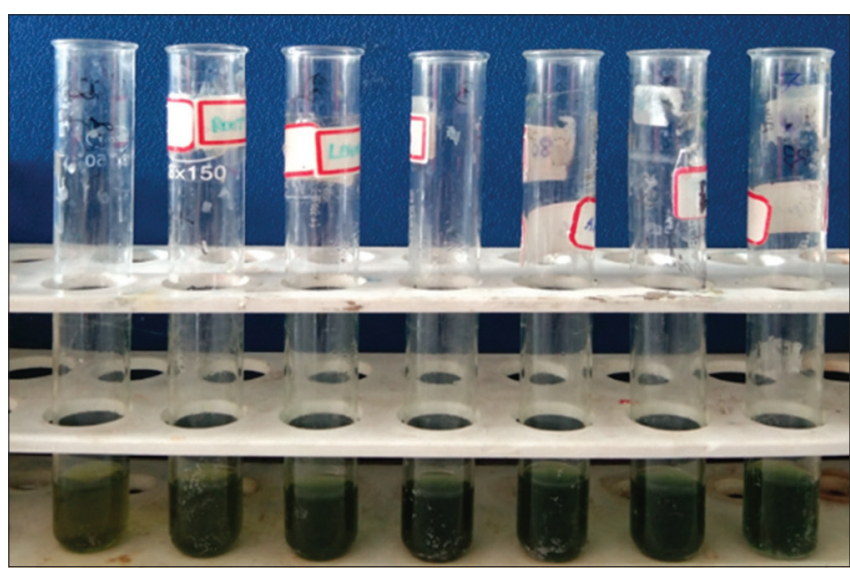

Fig. 2: Ferric reducing antioxidant power assay of hot air ovendried kiwi extract 
was taken out and centrifuged at $4000 \mathrm{rpm}$ for $10 \mathrm{~min}$, the supernatant was taken out. The supernatant was placed in a water bath at $95^{\circ} \mathrm{C}$ for the solvent to evaporate and stored at room temperature [12].

\section{RESULTS}

Ferric reducing antioxidant power assay results of naturally dried guava extract.

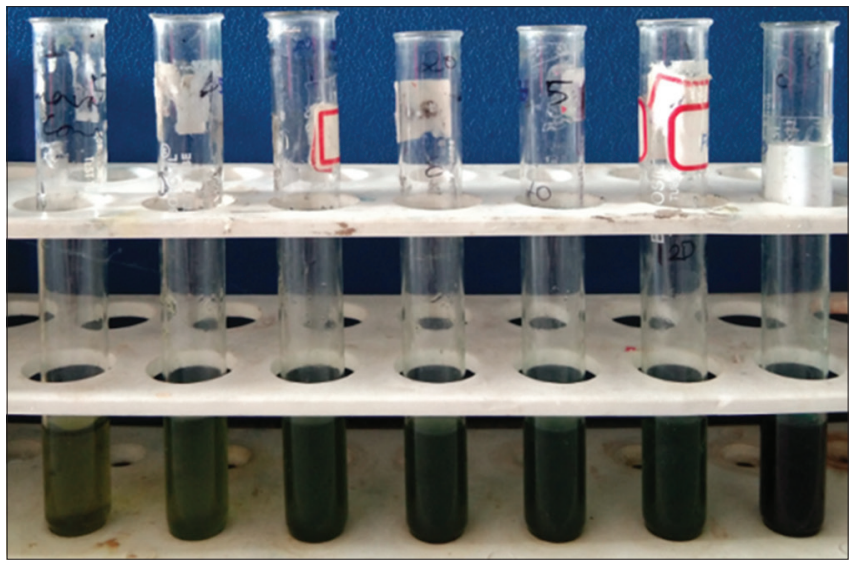

Fig. 3: Ferric reducing antioxidant power assay results of naturally dried guava extracts

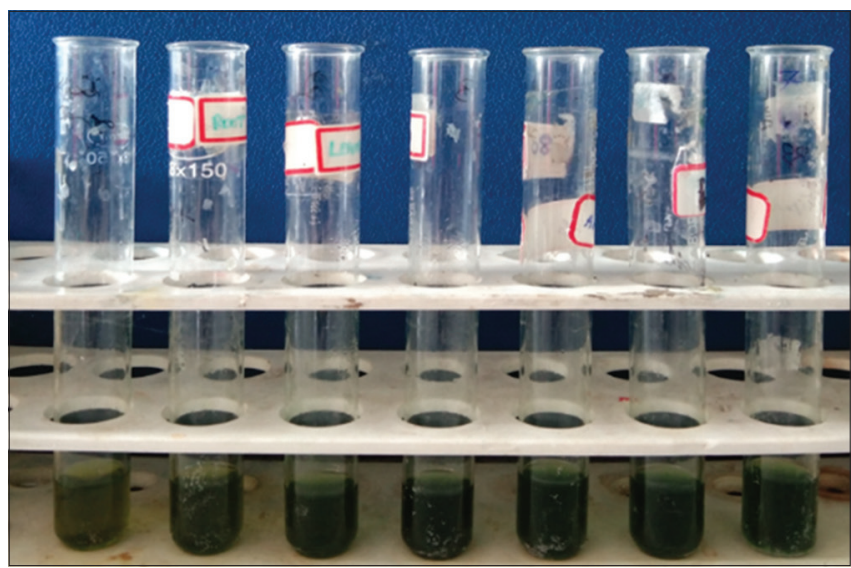

Fig. 4: Ferric reducing antioxidant power assay of hot air ovendried kiwi extract

\section{RESULTS AND DISCUSSION}

Table 1: Concentration, sample OD, and OD percentage of naturally dried guava extract.

Sample OD-control OD/sample OD multiplied by $100=0 D \%$.

Control OD of naturally dried guava extract $=0.139$.

Table 2: Concentration, sample OD, and OD percentage of naturally dried kiwi extract.

Sample OD-control OD/sample OD multiplied by 100=OD $\%$.

Control OD of naturally dried kiwi extract $=0.146$.

Table 3: Concentration, sample OD, and OD percentage of hot air ovendried guava extract.

Sample OD-control OD/sample OD multiplied by $100=0 D \%$.

Control OD of hot air oven-dried guava extract $=0.139$.

Table 4: Concentration, sample OD, and OD percentage of hot air ovendried kiwi extract.

Sample OD-control OD/sample OD multiplied by $100=0 D \%$.

Control OD of hot air oven-dried kiwi extract $=0.146$.

Fig. 1 represents FRAP results of different concentrations (control, $20,40,60,80,100$, and 120 [all in microgram per ml]) of naturally dried guava extract. Fig. 2 represents FRAP results of different concentrations (control, 20, 40, 60, 80, 100, and 120 [all in microgram per ml]) of naturally dried kiwi extract. Fig. 3 represents FRAP results of different concentrations (control, 20, 40, 60, 80, 100 , and 120 [all in microgram per $\mathrm{ml}$ ]) of hot air oven-dried guava extract. Fig. 4 represents FRAP results of different concentrations (control, 20, 40, 60, 80, 100, and 120 [all in microgram per ml]) of hot air oven-dried kiwi extract. Intensity of blue colour determine the presence of antioxidants. Of these, the naturally dried ethanolic $P$. guajava seed extracts sample 3 shows the highest antioxidant activity (Fig. 5). Sample 4 showed the lowest antioxidant activity according to the FRAP assay results.

FRAP assay was performed to determine the antioxidant activity of each sample. According to the FRAP results, P. guajava which was naturally dried and extracted has shown the highest antioxidant activity (sample 3) then followed by the samples S4, S1, and S2. The least activity is observed in the sample (S2).

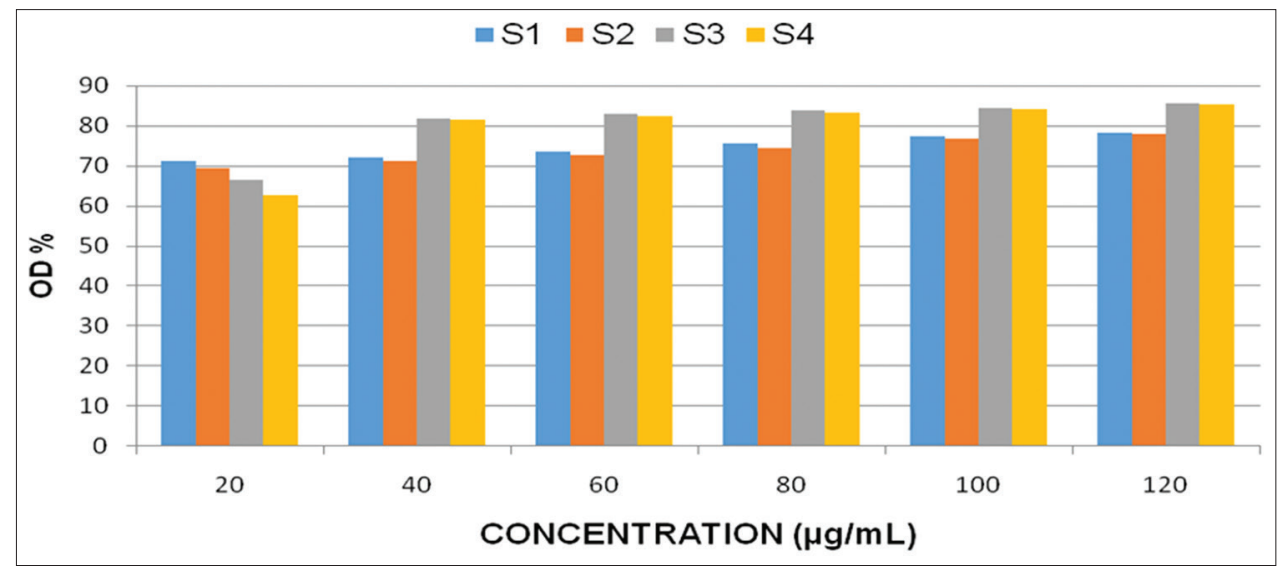

Fig. 5: Graphical representation of overall ferric reducing antioxidant power 


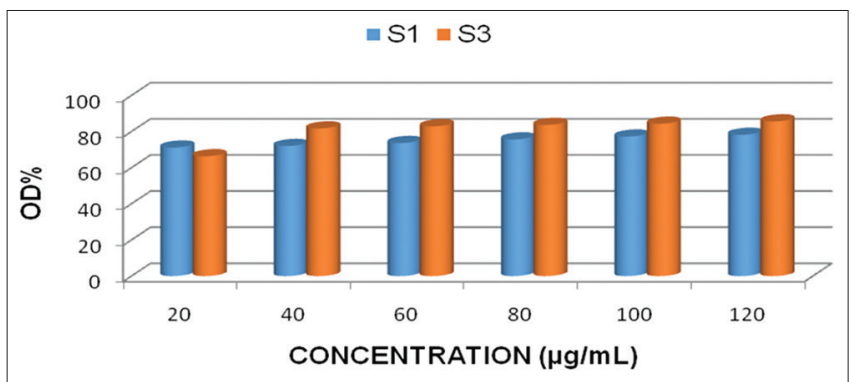

Fig. 6: Hot air oven drying ferric reducing antioxidant power results

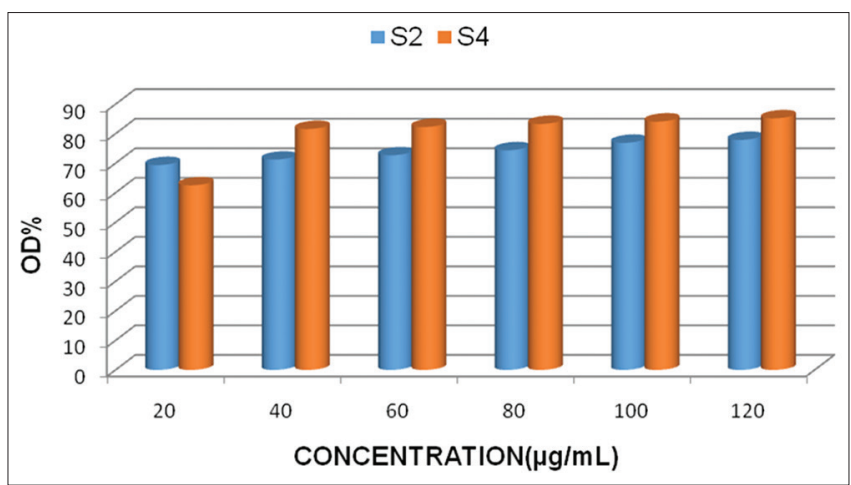

Fig. 7: Natural drying ferric reducing antioxidant power results

While comparing the natural drying and hot air oven drying, the hot air oven drying has a reducing effect on the antioxidant activity (Fig. 6), hence natural drying method is preferable than hot air oven drying. With the help of FRAP assay, we conclude that the natural drying is best than the hot air oven drying. Only at the concentration of $20 \mu \mathrm{g} / \mathrm{ml}$, the hot air oven-dried seed extracts (Fig. 6) (sample S2 and S4) have shown high antioxidant activity than the other two samples (Fig. 7) (sample S1 and S3) which were naturally dried and extracted.

\section{CONCLUSION}

While comparing the antioxidant activity between the $A$. deliciosa and $P$. guajava with the help of FRAP assay results, P. guajava has the highest amount of Vitamin C (responsible for antioxidant activity) and antioxidant capacity when compared to that of the A. deliciosa. Further work should be carried out to isolate and purify the bioactive compound responsible for antioxidant activity.

\section{ACKNOWLEDGMENTS}

The authors are thankful to Mr. G. Ramesh Kumar, Managing Director S.G.S Formulations Pvt. Ltd., Kakalur Industrial Estate, Tiruvallur, for providing us consultancy project. The authors are also thankful to Sankareswari and Rashi Chhetry for their support. The authors received five thousand rupees from S.G.S Formulations for completing the project.

\section{AUTHORS' CONTRIBUTIONS}

The authors declare that both authors contributed equally to this research article.

\section{REFERENCES}

1. Richardson DP, Ansell J, Drummond LN. The nutritional and health attributes of kiwifruit: A review. Eur J Nutr 2018;57:2659-76.

2. Kaur L, Rutherfurd SM, Moughan P, Drummond L, Boland MJ. Actinidin enhances gastric protein digestion as assessed using an in vitro gastric digestion model. J Agric Food Chem 2010;58:5068-73.

3. Stonehouse W, Gammon CS, Beck KL, Conion CA, Von Hurst PR, Kruger R. Kiwifruit: Our daily prescription for health. Can J Physiol Pharmacol 2013;91:442-7.

4. D’Evoli L, Moscatello A, Lucarini M, Aguzzi A, Gabrielli P, Battistelli A, et al. Nutritional traits and antioxidant capacity of kiwifruit (Actinidia deliciosa Planch., CV. Hayward) grown in Italy. J Food Compos Anal 2015;37:25-9.

5. Sato R, Dang KM, McPherson BG, Brown AC. Anticancer activity of Guva (Psidium guajava) extracts. J Complement Integr Med 2010;7:1-12.

6. Barbalho SM, Farinazzi-Machado FM, de Alvares Goulart R, Claudia A, Brunnati S, Ottoboni AM, et al. Psidium guajava (Guava): A plant of multipurpose medicinal applications. Med Aromat Plants 2012;4:1-6

7. Gutierrez RM, Mitchell SA, Solis RV. Psidium guajava: A review of its traditional uses, phytochemistry and pharmacology. J Ethnopharmacol 2008;117:1-27.

8. Prakash NK, Moorthy R, Sripriya N, Lakshmi RP, Santhanakrishnan D, Bhuvaneswari S. Antioxidant, free radical scavenging activity and GCMS studies of Pedilanthis tithymaloides (L) Poit. Int J Pharm Pharm Sci 2014;6:284-7.

9. Handa SS, Khanuja SP, Longo G, Rakesh DD. Extraction Technologies for Medicinal and Aromatic Plants. Trieste, Italy: ICSUNIDO; 2008

10. Oyaizu M. Studies on products of browning reactions: Anti oxidative activities of products of browning reaction prepared from glucosamine. Jpn J Nutr 1986;44:307-31.

11. Choudhury KD, Choudhury MD, Paul SB. Antioxidant activity of leaf extracts of Lasianthus lucidus Blume. Int J Pharm Pharm Sci 2012;4:533-5

12. Sajeesh T, Arunachalam K, Parimelazhagan T. Antioxidant and antipyretic studies on Pothos scandens L. Asian Pac J Trop Med 2011;4:889-99 